retained its popularity because it extracted easily weighable amounts of phosphoric oxide and of potassium. This advantage was lost when the modern turbimetric, colorimetric and spectrographic methods, with their ability to deal with amounts too small to be satisfactorily weighed, came into use.

These new methods, along with automatic balances and pipettes, had speeded up analytical determinations enormously and had vastly increased the number of analyses that could be undertaken; but it was easy to become so absorbed by the elegance of the methods and the beauty of the apparatus that one was apt to forget that the figures had little intrinsic value. Their use was for comparison with known or standard soils, so far as other conditions permitted comparison to be made. The greatest value of soil analysis was realized when it was done in conjunction with field experiments.

We had to-day obviously gone a long way from the ideas that formed the background of Dyer's early work. The nineteenth century was a time of great generalizations, majestic in their comprehensiveness, magnificent in their simplicity. In this century the accumulation of awkward facts had broken down the old generalizations. The modern idea was still more complex. We were at the stage of recognizing the complexities, but not yet of expressing them in terms of mathematical equations and degrees of statistical significance.

The methods were at present empirical, and that meant that the analyst had to have close contact with field experiments to satisfy himself that they were reliable. He had to have a mind sufficiently open to reject them when they ceased to be so, and sufficiently alert to devise others that would be better. That, however, was no new situation for a consulting chemist. His work lay largely in regions not yet tidied up by the science of the day; his equipment had always to be a wide knowledge of scientific methods combined with ingenuity of invention, soundness of judgment and complete intellectual integrity. It was because Bernard Dyer possessed these qualities in so marked a degree that we honoured his memory, and in the words of Ecclesiasticus, counted him among those "that have left a name behind them that their praises might be reported".

\section{SUPPLY AND DEMAND FOR PHYSICISTS}

$\mathrm{T}$ HE pamphlet "Present and Future Supply and Demand for Persons with Professional Qualifications in Physics"* is one of the series of five reports to which reference has been made in Nature (January 28, p. 125). A subcommittee, under the chairmanship of Lord Hankey and composed mainly of physicists, was appointed in September 1947 by the Technical Personnel Committee of the Ministry of Labour and National Service to examine the position regarding the probable demands for physicists in relation to the estimated supply over the next few years. The subcommittee included representatives of industry, the universities, technical colleges, government departments, and the Technical and Scientific Register of the Ministry of Labour and

* Ministry of Labour and National Service : Technical and Scientific Register. Present and Future Supply and Demand for Persons with Professional Qualiflcations in Physies. Pp. 32 . (London: H.M.
Stationery Office, 1949.) 6d. net.
National Service. The report was finally approved in October 1948.

For the purposes of the inquiry a physicist was defined as a person qualified by means of a university degree in physics or in general science with physics as a main subject, and the fields of employment surveyed by the subcommittee were confined to those purely in physics, although some consideration was given to those on the border-line of engineering and technology. A very careful analysis of the requirements of industry, the research associations, government departments, the universities, and the teaching profession, for the periods 1948-50, 1951-55 and 1956 onwards, is given in the pamphlet, and on page 16 there is a summary in tabular form which shows clearly the estimated annual demands for physicists in the various organisations. The period 1948-50 is now almost past history, and it must be obvious that the large figure of 350 required annually for the teaching profession out of a total estimated demand of 865 and a supply of approximately 700 has been by no means met. The large number of attractive posts in industry and government research must have been filled at the expense of the teaching profession. From 1951 onwards, except for the teaching profession, it is estimated that the demand for physicists will steadily decline from a total of approximately 750 to about 600 ; for government departments it should drop from 175 a year in 1948-50 to fifty in later years.

In its general conclusions the subcommittee states (p. 20), "it is clear that after 1952 there is a possibility of over-supply of physicists" ; but this is followed by the qualifications that it is not easy to forecast the future and that a purely quantitative assessment of the position may prove misleading. This conclusion of the subcommittee may quite easily be misinterpreted. Indeed, the Times Educational Supplement of December 16, 1949, commenting on the report, stated that physicists face "a bleak future", but in a subsequent letter (March 3) Lord Hankey has made it clear that there is no ground for taking such a gloomy view of the future of physicists. After 1952 there is a possibility of over-supply, not in the highest levels of research graduates, in which there will always be a shortage, but among the less able men. Even the latter may take some comfort from the fact that the subcommittee warns employers and government departments to have less regard for high academic qualifications and to consider also the importance of personal qualities and abilities. Further, the rapid expansion in the number of fields of application of physics means that an unpredictable number of so-called 'engineering physicists' may be absorbed in industry.

It is difficult to see, however, how the requirements of the teaching profession will ever be met, and particularly how the present deficiency in the number of physics teachers will ever be overcome. With the absence of sufficient good teachers of physics, the number of students wanting to read physics at the universities is bound to fall and the requirements in Great Britain of scientific man-power will not be met. The annual output of physics graduates from the universities is now about 750 . This represents a considerable increase above the pre-war number and even above that of the Barlow report; and, while every effort should be made to maintain the quality, it would appear, from the report, undesirable at present to limit or discourage the number of entrants to the university physics schools. 